\title{
TRANSLATIONAL STUDY ON THE UTILITY OF METFORMIN TREATMENT IN CARDIOVASCULAR DISEASES
}

Mohapradeep Mohan, A.R.Cameron, G. Rena, C.C Lang

Division of Molecular \& Clinical Medicine

University of Dundee, Scotland, UK DD1 9SY

\section{PRESSING THE NEED FOR REPURPOSING OLD DRUGS}

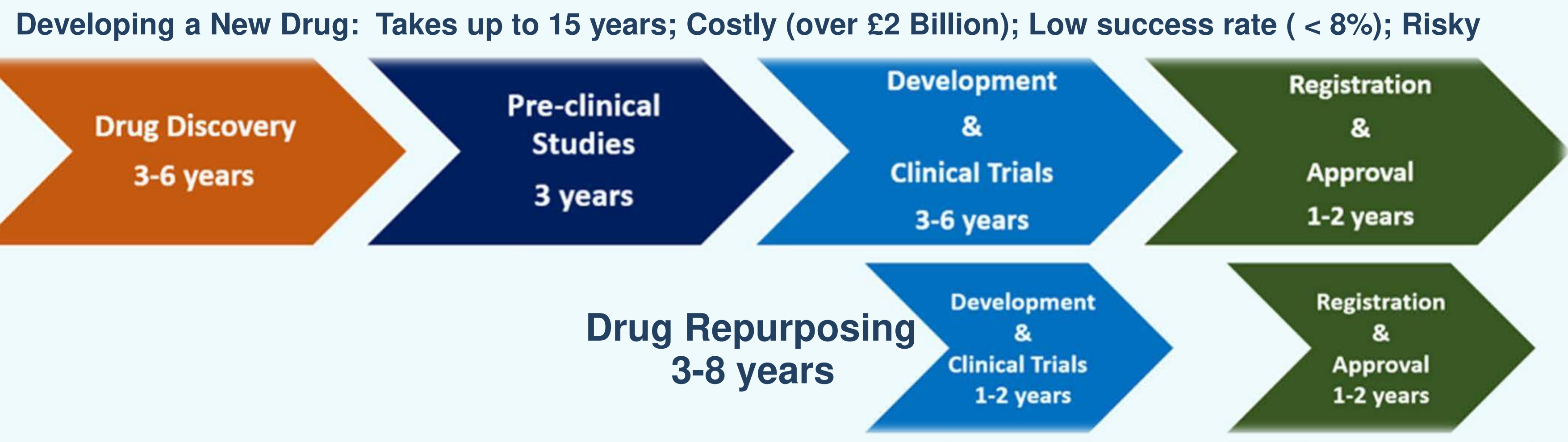

Drug repurposing builds on previous research and development and can bypass many of the challenges and hurdles of conventional drug development process.
$\checkmark$ Less expensive ( $£ 250$ million)
$\checkmark$ Less risky with high success rates.
$\checkmark$ Less time consuming (3-8 years)

\section{METFORMIN : OLD DRUG WITH NEW TRICKS}

- Metformin is a cheap (2p per pill), generic and the most commonly prescribed drug for type 2 diabetes that has been used for over 50 years.

- Inflammation is understood to contribute towards many diseases including cardiovascular diseases and diabetes.

Using a 'bench to bed side' approach, we studied the effect of inflammation and metformin use on prognosis in heart failure patients, and explored the anti-inflammatory effects of metformin using experimental and clinical studies.

\section{METFORMIN IS ASSOCAITED WITH BETTER SURVIVAL}

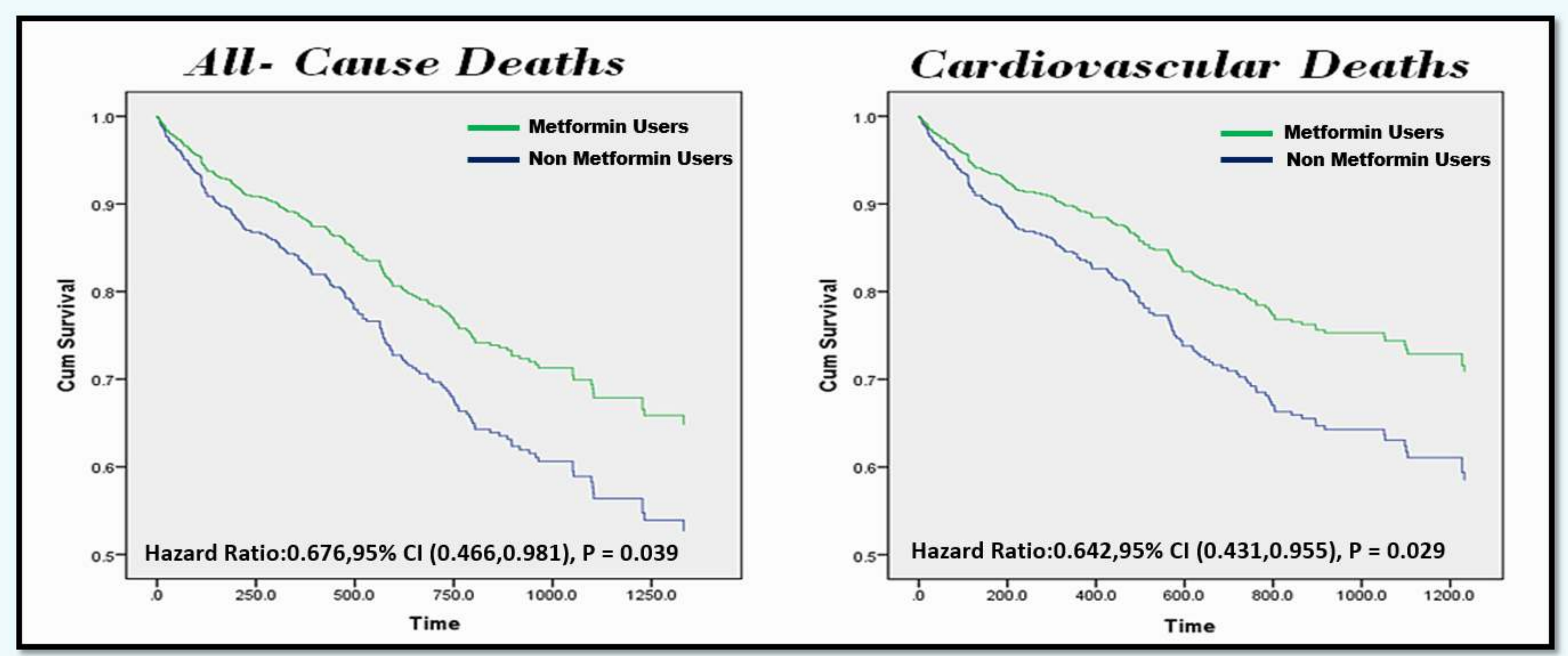

- Metformin use was associated with fewer deaths (36\% relative risk reduction) in heart failure patients with diabetes, suggesting a possible cardio-protective effect of metformin.

\section{INFLAMMATION IS HARMFUL IN CARDIAC PATIENTS}

Chronic inflammation enhances the risk of death in heart failure patients.

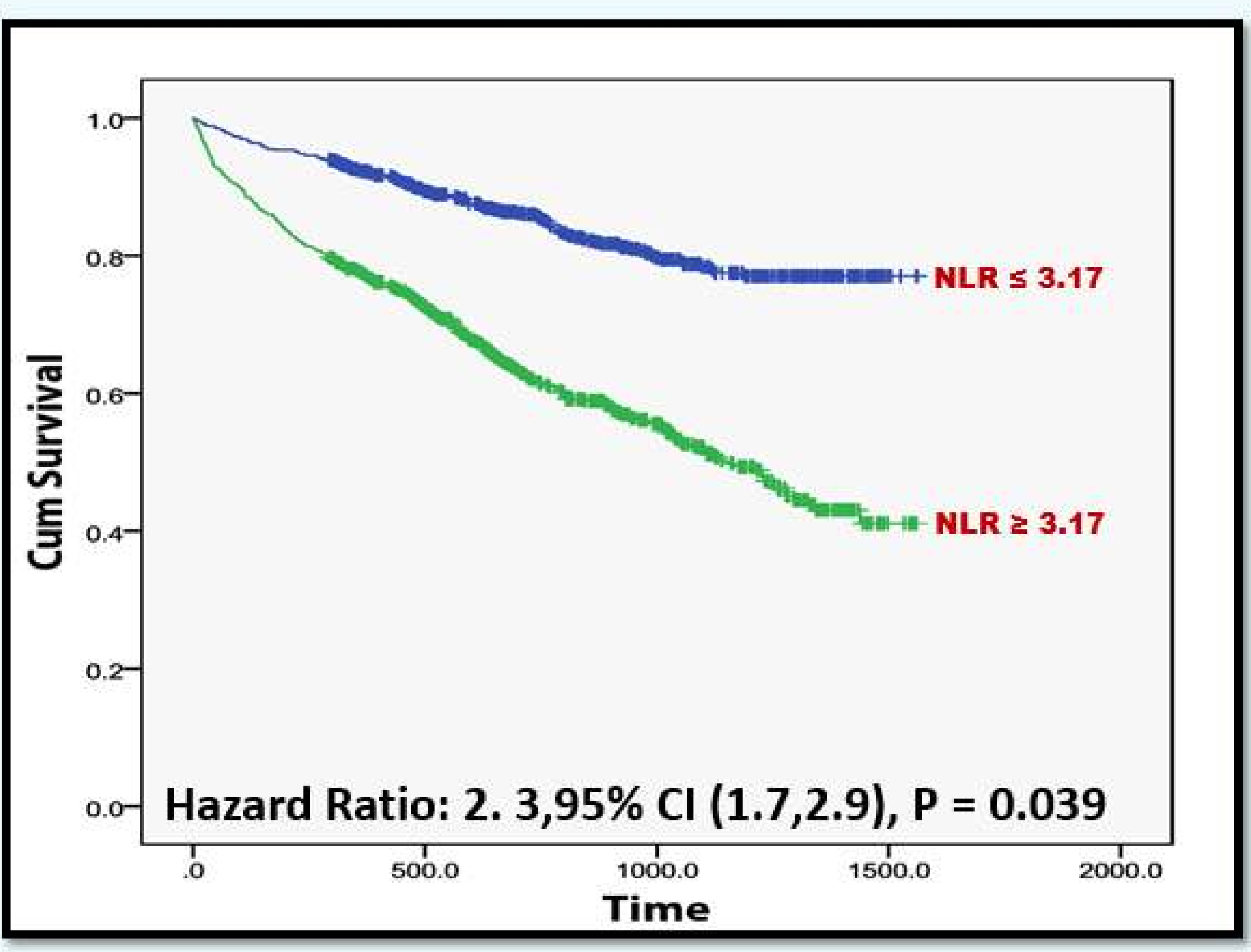

Neutrophil to lymphocyte Ratio (NLR); a marker of inflammation was associated with higher death rates in an observational study of 1660 patients with heart failure (1).
ANTI-INFLAMMATORY EFFECTS OF METFORMIN

A BENCH TO BEDSIDE STUDY

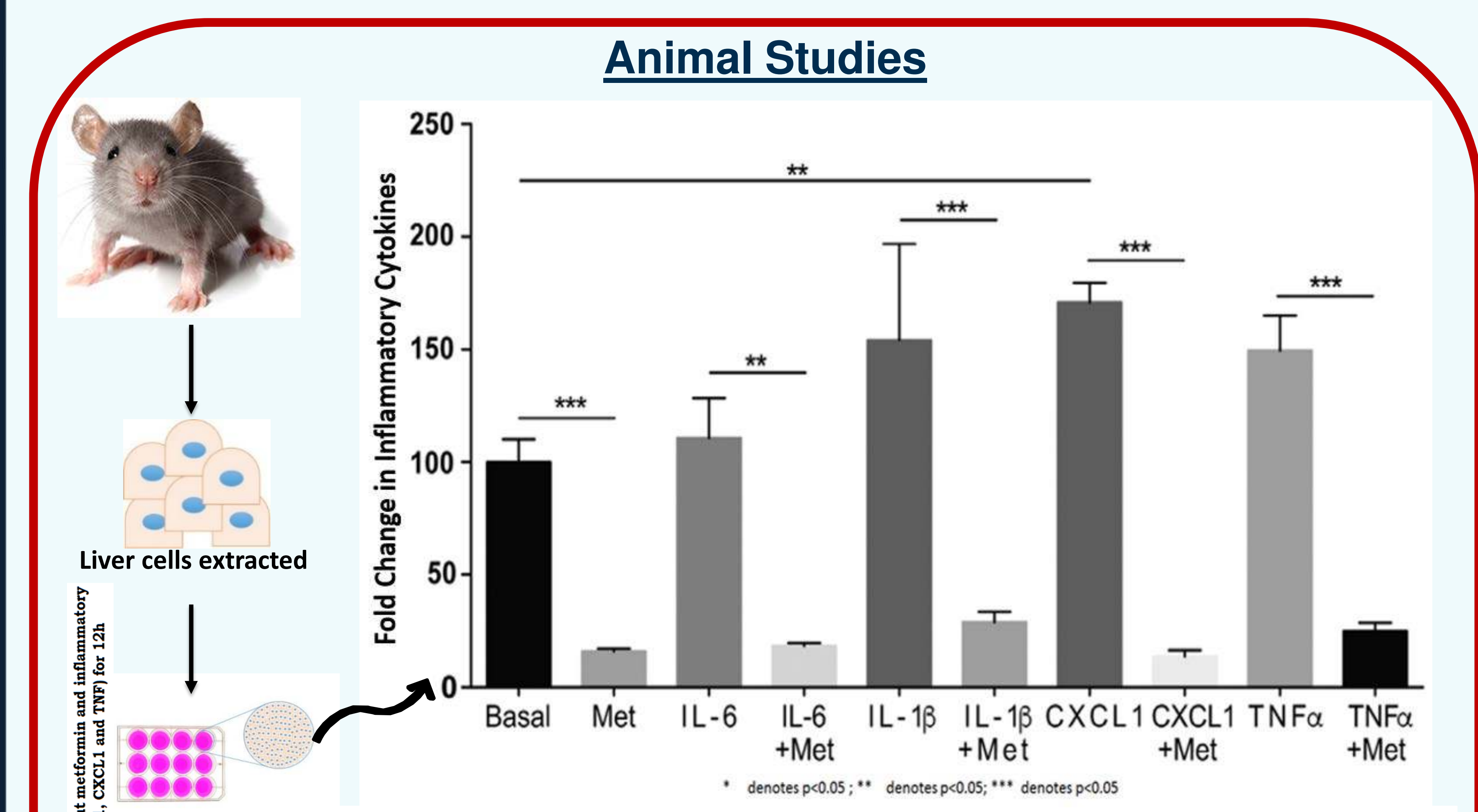

Effect of Metformin treatment on inflammatory cytokines in primary hepatocytes after Metformin treatment

- Metformin reduced expression of inflammatory markers interleukin6, interleukin-1 $\beta$, TNF- $\alpha$ and CXCL1/2 (2).
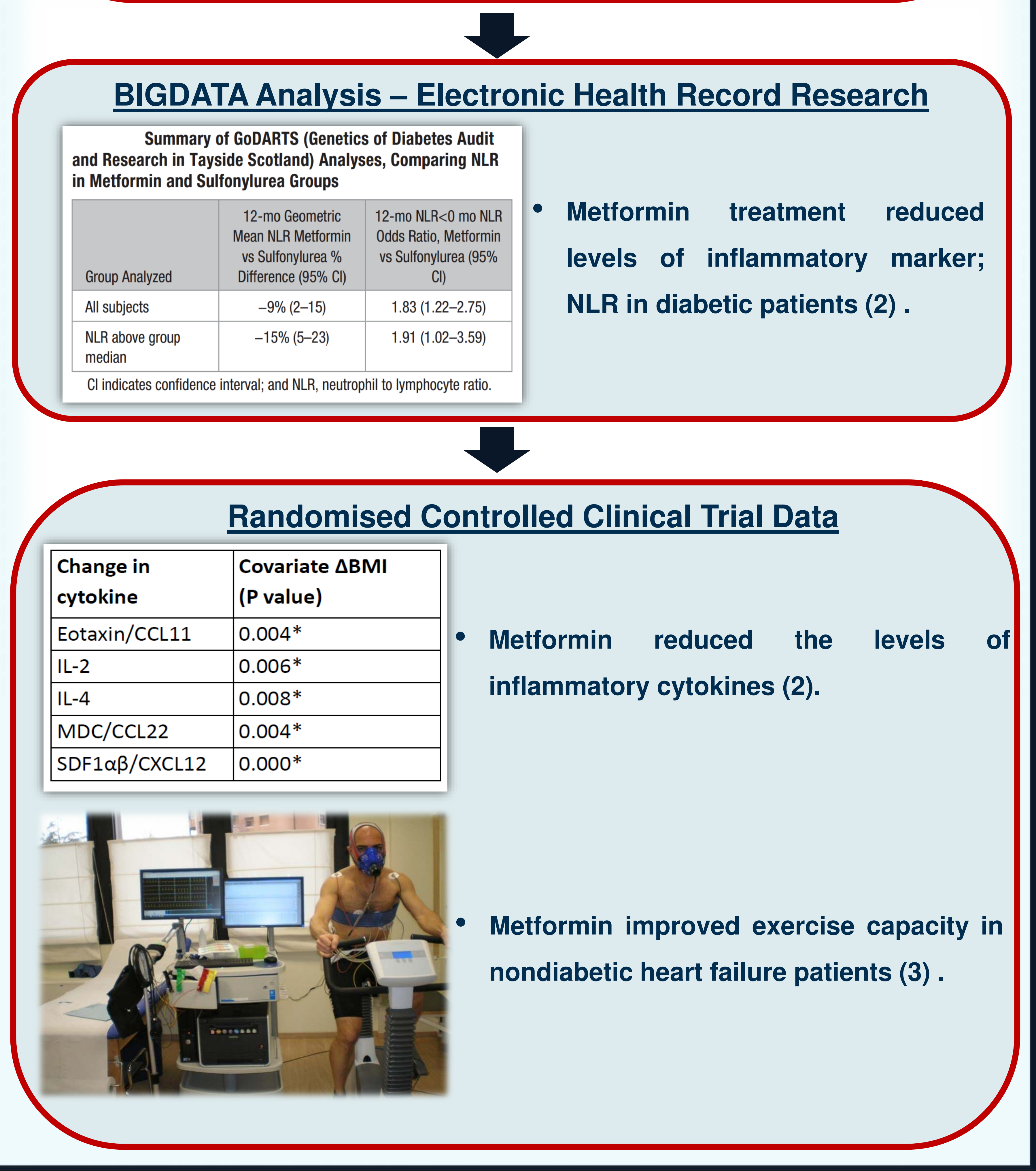

\section{SUMMARY / CONCLUSION}

Clinical evidence from our study suggest that a higher degree of inflammation bad in patients with heart disease and a potential survival benefit of metformin. - Using a translational approach, we have shown that metformin exerts antiinflammatory properties which may account for its unexplained cardio protective effects.

- Repurposing an existing drug such as metformin for CV disease has the potential of transforming lives globally.

References :
(1) Mohan M et al., (2014) Circulation. 130:A15218
(2) Cameron AR et al., (2016) Circ.Res. 119:652-665

(3) Wong AKF et al., (2012) European Journal of Heart Failure. 14:1303-1310 